\title{
Terapia por fonoforese com gel de copaifera duckei dwyer na reparação muscular
}

Phonophoresis therapy with copaifera duckei dwyer gel in muscle repair

Terapia de fonoforesis con gel copaifera duckei dwyer en reparación muscular

Daliane Ferreira Marinho ${ }^{1 *}$, Jairo Augusto Sousa Araújo $^{2}$, Eliane Ferreira Marinho ${ }^{3}$, Emanuele Ferreira Marinho ${ }^{4}$, Waldiney Pires Moraes ${ }^{2}$, Elaine Cristina Pacheco de Oliveira ${ }^{2}$, Adriana Caroprezo Morini².

\section{RESUMO}

Objetivo: Avaliar a ação terapêutica de um gel fitoterápico do oleorresina (OR) de C. duckei administrado através do método de fonoforese sobre a fase inflamatória do processo de reparação muscular. Métodos: Foi realizada uma pesquisa experimental com a produção de um gel de C. duckei a $10 \%$ e em seguida sua administração por fonoforese sobre o músculo gastrocnêmio submetido a trauma induzido por mecanismo tipo queda livre, a fim de analisar sua ação sobre a fase inflamatória do processo de recuperação muscular, considerando-se as variáveis de análise histológica: fibrose, necrose, edema, infiltrado inflamatório e células com núcleos centralizados. Os dados relativos a estas análises foram tabulados em planilhas do software Excel e receberam tratamento estatístico pelo software BioEstat 5.3. Para este estudo experimental foi admitido o nível de significância de 0,05 ( $\alpha=0,05$ ou $5 \%$ ), para um erro amostral de $5 \%$ em todas as análises. Resultados: Foram encontrados resultados terapêuticos significativos para as variáveis edema e necrose no grupo tratado com gel de copaiba administrado por fonoforese, quando comparados aos outros grupos. Conclusão: A recuperação de lesões musculares com gel de copaiba administrado por fonoforese apresentou-se positiva para o controle do edema e da formação de necrose no tecido muscular.

Palavras-chave: Copaifera, Ultrassom, Fonoforese, Músculo esquelético.

\begin{abstract}
Objective: To evaluate the therapeutic action of a phytotherapeutic gel of oleoresin (OR) of C. duckei administered through the method of phonophoresis on the inflammatory phase of the muscle repair process. Methods: An experimental research was carried out with the production of a $10 \% \mathrm{C}$. duckei gel and then its administration by phonophoresis on the gastrocnemius muscle submitted to trauma induced by a free fall mechanism, in order to analyze its action on the phase inflammatory process of muscle recovery, considering the histological analysis variables: fibrosis, necrosis, edema, inflammatory infiltrate and cells with centralized nuclei. The data related to these analyzes were tabulated in Excel spreadsheets and received statistical treatment by the BioEstat 5.3 software. For this experimental study, the significance level of 0.05 ( $\alpha=0.05$ or $5 \%$ ) was accepted, for a sampling error of $5 \%$ in all analyzes. Results: Significant therapeutic results were found for the variables edema and necrosis in the group treated with copaiba gel administered by phonophoresis, when compared to the other groups. Conclusion: The recovery of muscle injuries with copaiba gel administered by phonophoresis was positive for the control of edema and the formation of necrosis in muscle tissue.
\end{abstract}

Keywords: Copaifera, Ultrasound, Phonophoresis, Skeletal muscle.

1 Universidade do Estado do Pará (UEPA), Santarém - PA. *E-mail: daliane.marinho@uepa.br

2 Universidade Federal do Oeste do Pará (UFOPA), Santarém - PA.

${ }^{3}$ Centro Universitário da Amazônia (UNAMA), Santarém - PA.

${ }^{4}$ Universidade do Estado do Pará (UEPA), Belém - PA. 


\section{RESUMEN}

Objetivo: Evaluar la acción terapéutica de un gel fitoterapéutico de oleorresina (OR) de C. duckei administrado mediante el método de fonoforesis en la fase inflamatoria del proceso de reparación muscular. Métodos: Se realizó una investigación experimental con la producción de un 10\% de gel C. duckei y luego su administración por fonoforesis en el músculo gastrocnemio sometido a un trauma inducido por un mecanismo de caída libre, para analizar su acción en la fase proceso inflamatorio de recuperación muscular, considerando las variables de análisis histológico: fibrosis, necrosis, edema, infiltrado inflamatorio y células con núcleos centralizados. Los datos relacionados con estos análisis se tabularon en hojas de cálculo Excel y recibieron el tratamiento estadístico por el software BioEstat 5.3. Para este estudio experimental, se aceptó el nivel de significancia de 0.05 ( $\alpha=0.05$ o 5\%), para un error de muestreo del $5 \%$ en todos los análisis. Resultados: Se encontraron resultados terapéuticos significativos para las variables edema y necrosis en el grupo tratado con gel de copaiba administrado por fonoforesis, en comparación con los otros grupos. Conclusión: La recuperación de lesiones musculares con gel de copaiba administrado por fonoforesis fue positiva para el control del edema y la formación de necrosis en el tejido muscular.

Palabras clave: Copaifera, Ultrasonido, Fonoforesis, Músculo esquelético.

\section{INTRODUÇÃO}

Dentre as patologias tratadas pelas ciências da reabilitação, as que desencadeiam quadros inflamatórios em decorrência de lesões musculares traumáticas estão entre as mais recorrentes, o que aumenta a importância de se descobrirem novas e eficientes terapias anti-inflamatórias e de reparação tecidual, principalmente as que minimizem os efeitos colaterais dos fármacos atualmente utilizados. Destacam-se nesse sentido as pesquisas que visam o emprego de substâncias naturais, dentre elas as que exploraram o efeito anti-inflamatório e cicatrizante do óleorresina (OR) de copaíba s.p. (MONTES LV, et al., 2009; SOUSA FILHO LF, et al., 2017).

A lesão no tecido muscular leva a alterações na funcionalidade do sistema. Esta ocorre devido a mecanismos diversos, como forças diretas (lacerações e contusões), e forças indiretas (tensão exercida sobre o músculo) (TOMASONI SS, 2011). Os danos musculares traumáticos diretos podem resultar em profundas alterações histopatológicas e na perda transitória da função muscular, que pode vir a se tornar uma perda definitiva após duas semanas ou mais, dependendo da amplitude da lesão e da qualidade do processo de recuperação tecidual (RIBEIRO R, 2009).

De forma didática, o processo de regeneração do tecido muscular após uma lesão é dividido em três fases. A primeira é a fase inflamatória aguda ou de destruição, que ocorre de 0 a 7 dias (edema, hematoma, fibrina e infiltrado de células inflamatórias). A segunda fase, a proliferativa, de 7-21 dias (fagocitose, coagulação de fibrina, proliferação de fibroblastos e miofibroblastos, crescimento sinovial e capilar). A terceira fase, de maturação e remodelamento, 21 dias ou mais (maturação das miofibras, diminuição gradual do volume de capilares, organização das fibras de colágeno tipo I, restauração da capacidade funcional do músculo reparado (JARVINEN TA, et al., 2005).

O OR de copaíba, entre as suas mais diversas espécies, é há muito tempo conhecido por suas propriedades medicinais, e utilizado por comunidades tradicionais, principalmente na região norte do Brasil, como um recurso natural no tratamento de diversas doenças. Estas doenças são aquelas que geralmente cursam com quadros inflamatórios, e com cicatrização de feridas e tecidos, por exemplo. Muitos desses efeitos já foram testados e comprovados através de pesquisas científicas, principalmente seus efeitos antiinflamatório, antifúngico e cicatrizante (CARVALHO JCT, et al., 2005; PIERI FA, et al., 2009).

Já o ultrassom (US) terapêutico é conhecido como uma das terapias físicas mais utilizadas na Fisioterapia. Ele é classificado como um recurso terapêuticos de eletrotermoterapia, e sua ação ocorre sobre o controle do processo inflamatório, e sobre a aceleração do processo de cicatrização tecidual. Existem diversas formas de aplicação do US terapêutico, a do contato direto, a subaquática, e a por 
fonoforese. A técnica por fonoforese consiste na aplicação transdérmica de substâncias através das ondas mecânicas produzidas pelo equipamento de US. Essa forma de aplicação é escolhida pelo terapeuta a fim de combinar os efeitos de ambas as terapias e minimizar os efeitos colaterais dos fármacos no sistema gástrico, por ter aplicação direta sobre o local da lesão e evitar a passagem do fármaco pelo sistema digestivo (OLIVEIRA RF, et al., 2011; VICTOR EG, et al., 2012).

Existem alguns estudos que já testaram a utilização da fonoforese na administração de fármacos tópicos, principalmente os com ação anti-inflamatória (KOEKE PU, et al., 2005; SILVEIRA PCL, et al., 2010; SOUZA J, et al.,2013). Porém, quando pensamos na aplicação associada de um fármaco natural ou fitoterápico, como o OR de copaíba, através do método de fonoforese, ainda são poucas as pesquisas desenvolvidas, e inexistentes em relação à espécie C. duckei (LIMA TCP, et al., 2020).

Com esta pesquisa pretende-se ingressar no campo de discussões em torno da administração por fonoforese, para o tratamento do processo inflamatório agudo de uma lesão muscular de origem traumática. O estudo também procura encontrar evidências para os relatos do fato de que esse fármaco natural quando aplicado através da terapia de fonoforese mantém o seu efeito terapêutico ou o potencializa através de tal associação. Isso por meio de uma análise realizada durante a fase inflamatória do processo de reparação de uma lesão muscular de origem traumática. Deste modo, o objetivo desse estudo foi avaliar a ação terapêutica de um gel fitoterápico com OR de C. duckei administrado através do método de fonoforese, na fase inflamatória do processo de reparação muscular.

\section{MÉTODOS}

A pesquisa foi realizada através de uma pesquisa experimental, por meio de uma abordagem quantitativa. Foram utilizados ratos da espécie Rattus norvegicus albinus e linhagem Wistar, machos adultos sadios em número de 40 (quarenta), com idade superior a 90 (noventa) dias e peso entre 300 (trezentos) e 350 (trezentos e cinqüenta) gramas. Todos provenientes do biotério da Universidade Federal do Oeste do Pará (UFOPA), Campus Tapajós. Os animais foram divididos em grupos compostos por cinco animais cada $(n=5)$, distribuídos de forma aleatória.

Esta pesquisa seguiu as normas do Colégio Brasileiro de Experimentação Animal (COBEA) e legislação nacional para vivissecção animal em vigor, foi aprovada pelo Comitê de Ética em Uso de Animais da Universidade Federal do Oeste do Pará segundo o parecer № 09007-2013. Foi ainda cadastrado e aprovado no SISBIO/ICMBio com obtenção da autorização sob № 44266-2, necessária para pesquisas realizadas com produtos oriundos de reservas florestais.

O gel foi formulado na concentração a $10 \%$ de OR da espécie C. duckei, tendo o OR as seguintes especificações: coletado no período chuvoso, de árvores identificadas localizadas no $\mathrm{Km} 83$ da Floresta Nacional do Tapajós (FLONA), com exsicatas depositadas no Herbário da Embrapa Amazônia Oriental (registro C. duckei - NID 69/2011). E o OR foi caracterizado quimicamente através de cromatografia gasosa acoplada à espectrometria de massa. A formulação do gel com OR de $\mathrm{C}$. duckei seguiu as recomendações da Farmacopeia Brasileira de 2011.

Na pesquisa o gel fitoterápico produzido foi testado através da sua aplicação de forma tópica e através da técnica de fonoforese. Para a fonoforese foi utilizado o aparelho de ultrassom (US) Sonopulse Special, fabricado pela lbramed, na frequência de $1 \mathrm{MHz}$, com ERA de $1 \mathrm{~cm}^{2}$. Os demais parâmetros físicos do US utilizados no teste terapêutico foram: modo de corrente pulsado (frequência do pulso $=100 \mathrm{~Hz}-20 \%$ ); intensidade média de $0,6 \mathrm{~W} / \mathrm{cm}^{2}$; tempo de aplicação de $1 \mathrm{mim} / \mathrm{cm}^{2}$, através de contato direto, com movimento circular do cabeçote, em sentido horário, por toda a extensão da região do dorso e membro posterior direito. A proporção utilizada foi a de $0,5 \mathrm{ml}$ de gel por aplicação, sendo uma aplicação a cada 24 horas por até seis dias consecutivos.

Para o protocolo de pesquisa experimental foi necessária à produção de lesões musculares traumáticas padronizadas. Estas ocorreram com os animais sob efeito anestésico, através de um mecanismo de contusão tipo queda livre, adaptado de McBrier NM, et al. (2009), que consistiu em uma plataforma dupla de 
madeira transpostas em seu centro por uma peça de Policloreto de Vinila (PVC). A lesão foi produzida no membro posterior direito do animal, após epilação, sobre os músculos gastrocnêmio e sóleo, A eutanásia dos animais para coleta do tecido muscular a ser analisado ocorreu através da superdose de anestésicos.

Os animais foram divididos em quatro grupos com $(n=10)$. Cada um dos quatro grupos de pesquisa foi composto de 2 subgrupos com $(n=5)$. Sendo que estes subgrupos foram distintos entre si de acordo com o momento de eutanásia. O primeiro subgrupo foi identificado como o da eutanásia no $2^{\circ}$ dia (48h), que correspondeu ao auge do início da fase aguda inflamatória da lesão traumática, e o segundo subgrupo foi identificado como o da eutanásia no $7^{\circ}$ dia após a lesão, que correspondeu ao final da "fase inflamatória aguda" ou "fase de destruição" e início da "Fase proliferativa".

Esses momentos de eutanásia foram escolhidos devido ao objetivo desse estudo de analisar a ação do OR aplicado via fonoforese, durante a primeira fase do processo de reparo do tecido muscular, que corresponde à fase inflamatória. Os quatro grupos estudados foram assim instituídos:

Grupo controle: Sofreu lesão traumática por contusão e não recebeu nenhuma forma de tratamento. Com dois momentos de eutanásia (24h e no $7^{0}$ dia após a lesão). Grupo ultrassom (US) convencional: Sofreu lesão traumática por contusão e como tratamento a aplicação do ultrassom com gel convencional segundo os parâmetros selecionados. Com dois momentos de eutanásia, $24 \mathrm{~h}$ após a lesão com uma aplicação de tratamento $(n=5)$ e no $7^{\circ}$ dia após a lesão $(n=5)$, com 6 dias de tratamento.

Grupo gel de copaíba 10\% uso tópico: Sofreu lesão traumática por contusão e como tratamento a aplicação do gel de C. duckei a 10\% na forma tópica. Também com dois momentos de eutanásia (24h e no $7^{\circ}$ dia após a lesão). Grupo copaíba fonoforese: Sofreu lesão traumática por contusão e como tratamento a aplicação do ultrassom com gel de C. duckei a 10\% (fonoforese), segundo os parâmetros selecionados. Com dois momentos de eutanásia (24h e no $7^{\circ}$ dia após a lesão).

Os músculos extraídos após a eutanásia foram armazenados em paraformol a $4 \%$, posteriormente seguiram para processamento histopatológico, sendo foram corados através da técnica de hematoxilina e eosina (HE). Foram analisados ao microscópio óptico comum e fotografados através de uma câmera de microfotografia conectada a um microcomputador. As fotografias para análise foram obtidas através de um aumento de $4 x, 10 x$ e 40x.

A análise histopatológica foi realizada de forma cega e com a utilização de microscopia óptica de forma quantitativa, tendo por objetivo definir graus e valores para as seguintes variáveis de interesse: 1. células com núcleos centralizados; 2 . fibrose; 3. edema; 4 . necrose e 5. células de infiltrado inflamatório.

Para o estudo análise quantitativa foram tomadas as medidas de um campo de análise aleatório, onde foram mensuradas as áreas em micrômetros de fibrose, de edema e necrose. Já para os itens células do infiltrado inflamatório e de células com núcleo centralizado, estas foram quantificadas por número de células/campo selecionado. Para isso foi utilizado um microscópio com câmera acoplada e as medidas foram tomadas através do Software Módulo de Imagem Motic live 2.0, com resolução 1280x1024.

Para as áreas de fibrose e edema e para contagem do número de células do infiltrado inflamatório foi utilizada a objetiva de $4 x$, para as áreas de necrose foi utilizada a objetiva de $10 x$ e para núcleos centralizados as objetivas de $4 \mathrm{x}$ e $10 \mathrm{x}$. Os resultados foram atribuídos por variáveis ordenativas e numéricas e foram empregados diferentes testes estatísticos para as comparações entre os grupos e subgrupos.

Os dados da pesquisa foram coletados e armazenados para posterior análise estatística. Para isso foi utilizado o software Microsoft Excel 2007, e o tratamento estatístico de comparação entre grupos foi realizado pelo software BioEstat 5.3.

Os grupos foram analisados e comparados entre si considerando-se suas médias e desvios padrão, e passaram por testes de normalidade com Shapiro Wilk, onde para as amostras consideradas normais foi utilizado o teste paramétrico ANOVA mais Tukey e, para as amostras consideradas não-normais foi utilizado o teste não-paramétrico de Kruskall-walis. Sendo que para esse estudo experimental foi admitido o nível mínimo de significância considerando o valor de $p \leq 0,05$. 


\section{RESULTADOS}

Para a apresentação dos resultados obtidos no teste de ação terapêutica com gel de C. duckei $10 \%$ estes levaram em consideração as variáveis de interesse para a pesquisa analisadas separadamente, entre elas e entre os momentos de eutanásia (48h e no $7^{\circ}$ dia após o trauma).

\section{Fibrose}

Quanto à fibrose esta foi analisada de acordo com a área em micrômetros $(\mu \mathrm{m})$. Foi possível observar que no momento 48h após a lesão o grupo com maior área de fibrose foi o grupo US, seguido do grupo fonoforese e do grupo tópico, em relação ao grupo controle, que foi o com a menor área de fibrose observada. E já quando observamos o momento $7^{\circ} \mathrm{dia}$, a terapia que menos apresentou área de fibrose foi o grupo US, seguido do grupo fonoforese e do grupo tópico.

Em relação à formação de fibrose foi possível constatar que nas primeiras $48 \mathrm{~h}$ após a lesão o mais indicado seria a utilização do tratamento com gel de C. duckei 10\% de forma apenas tópica e após esse momento o mais indicado seria a utilização de US ou a fonoforese com o gel do OR para o controle do processo cicatricial. Mas, apesar dessas diferenças perceptíveis ao gráfico, quando comparados mediante teste de variância não houve significância estatística entre os grupos de tratamento, tanto $48 \mathrm{~h}$ após 0 trauma como no $7^{0}$ dia em relação ao grupo controle ou entre eles (Gráfico 1).

Gráfico 1 - Área de formação de fibrose (em $\mu \mathrm{m}$ ) nos diferentes momentos de eutanásia (48h e $7^{\circ}$ dia). Os resultados estão expressos em média ( $n=5 /$ grupo).

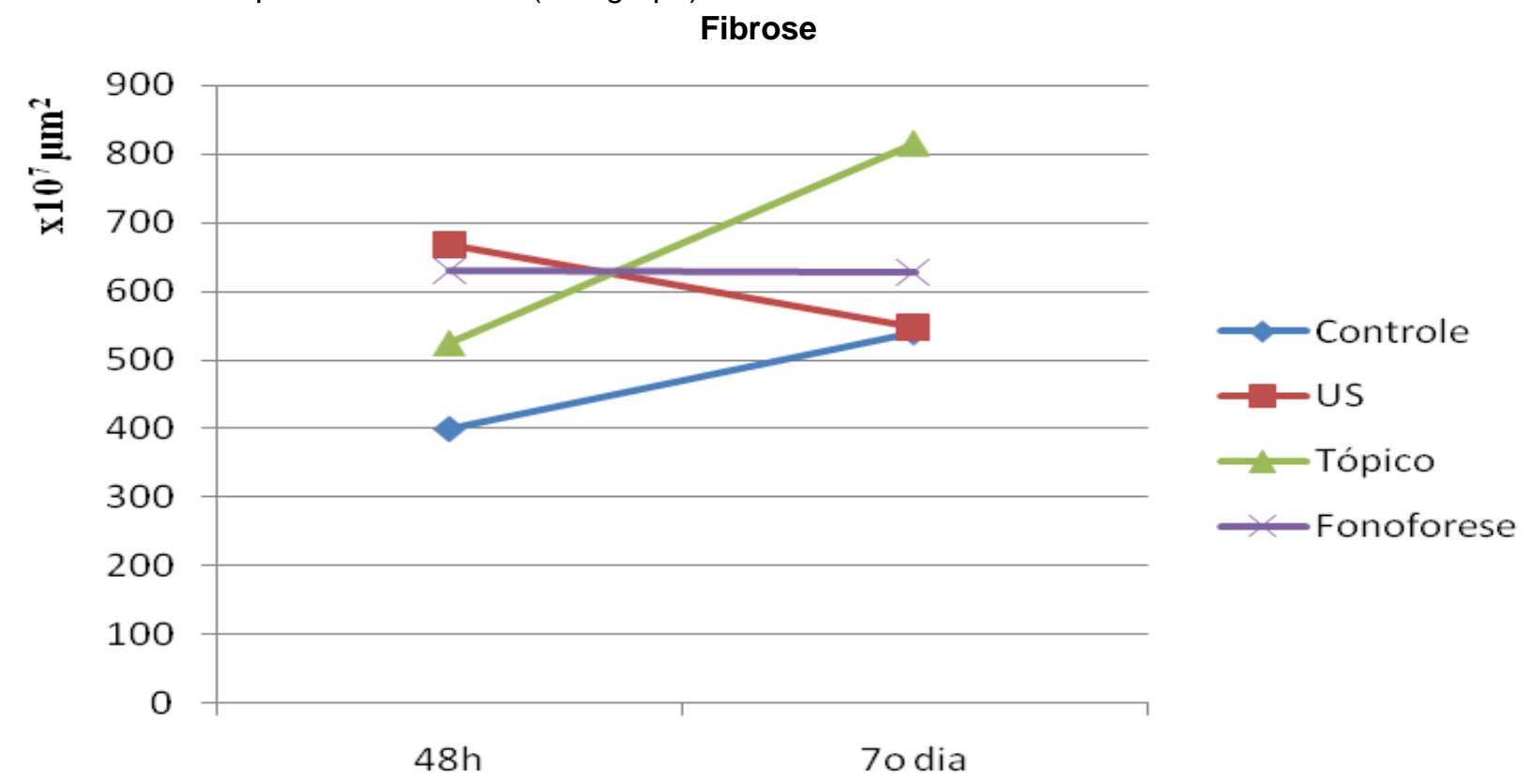

Fonte: Marinho, DF, et al., 2017.

Momento de Eutanásia

\section{Edema}

Em relação à variável edema esta foi analisada de acordo com a área em micrômetros $(\mu \mathrm{m})$. $\mathrm{O}$ tratamento que no momento $48 \mathrm{~h}$ apresentava a menor área de edema foi à terapia por fonoforese, seguido da terapia por uso tópico e depois a terapia por US. Já no momento $7^{\circ}$ dia a terapia que apresentava menor área de edema foi a de uso tópico, seguido do grupo fonoforese e do grupo US em relação ao grupo controle. No entanto, os resultados não apresentaram significância em relação ao grupo controle, nos dois momentos de eutanásia. No entanto, quando comparados entre si, houve significância entre o resultado dos grupos Tópico $48 \mathrm{~h}$ e Tópico $7^{\circ}$ dia. Bem como houve significância entre os grupos testados Fonoforese $48 \mathrm{~h}$ e Fonoforese $7^{\circ}$ dia (Gráfico 2). 
Gráfico 2 - Área de edema (em $\mu \mathrm{m})$ nos diferentes momentos de eutanásia (48h e $7^{\circ}$ dia). Os resultados estão expressos em média ( $n=5 / g r u p o)$.

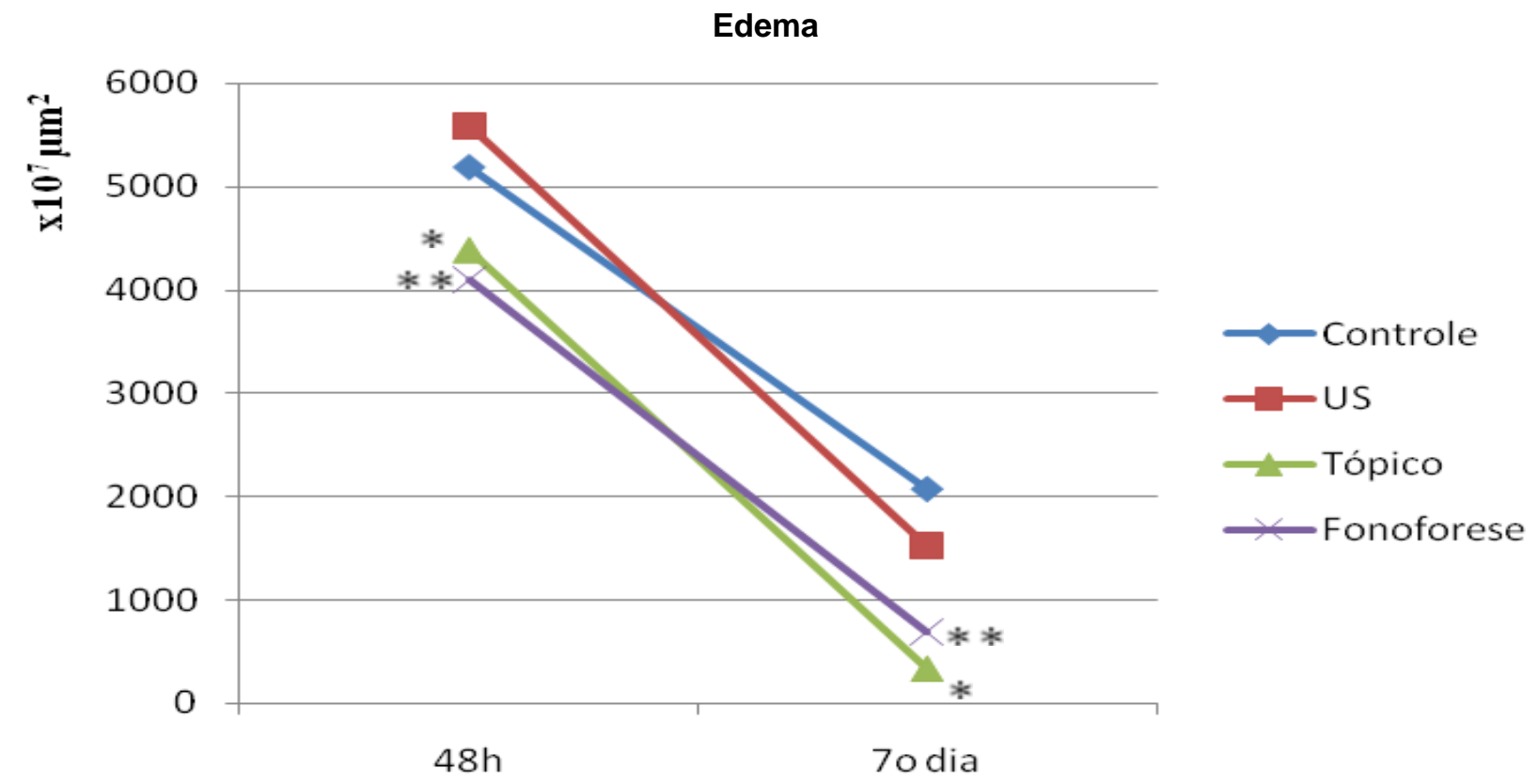

Momento de Eutanásia

Legenda: *Houve significância entre as terapias por uso Tópico 48 e Tópico $7^{\circ}$ dia quanto a formação da área de edema. ${ }^{* *}$ Houve significância entre as terapias por Fonoforese 48 e fonoforese $7^{\circ}$ dia quanto a formação da área de edema.

Fonte: Marinho, DF, et al., 2017.

\section{Necrose}

Em relação à formação de necrose esta foi analisada de acordo com a área em micrômetros ( $\mu \mathrm{m})$. Sendo que no momento $48 \mathrm{~h}$ a terapia onde houve a menor formação de áreas de necrose foi no grupo fonoforese, seguido pela terapia com US e em uso tópico. Sendo que, tanto a terapia por US como a por uso tópico tiveram resultados piores que o do grupo controle. Havendo significância entre os resultados das terapias com US e Tópico em relação ao grupo controle.

Em relação ao momento $7^{\circ}$ dia a menor área de formação de áreas de necrose foi no grupo tópico, seguido da terapia por fonoforese e pela terapia de US, sendo que todas tiveram resultados melhores que do grupo controle. No entanto, não houve significância entre os tratamentos testados no momento $7^{\circ}$ dia.

Quando comparados os resultados entre momentos diferentes de eutanásia, foi possível observar significância entre as terapias US 48h e US $7^{0}$ dia e entre as terapias uso Tópico $48 \mathrm{~h}$ e Tópico $7^{\circ}$ dia, bem como nas terapias Fonoforese $48 \mathrm{~h}$ e Fonoforese $7^{\circ}$ dia (Gráfico 3). 
Gráfico 3 - Área de necrose $(e m \mu m)$ nos diferentes momentos de eutanásia (48h e $7^{\circ}$ dia). Os resultados estão expressos em média ( $n=5 / g r u p o)$.

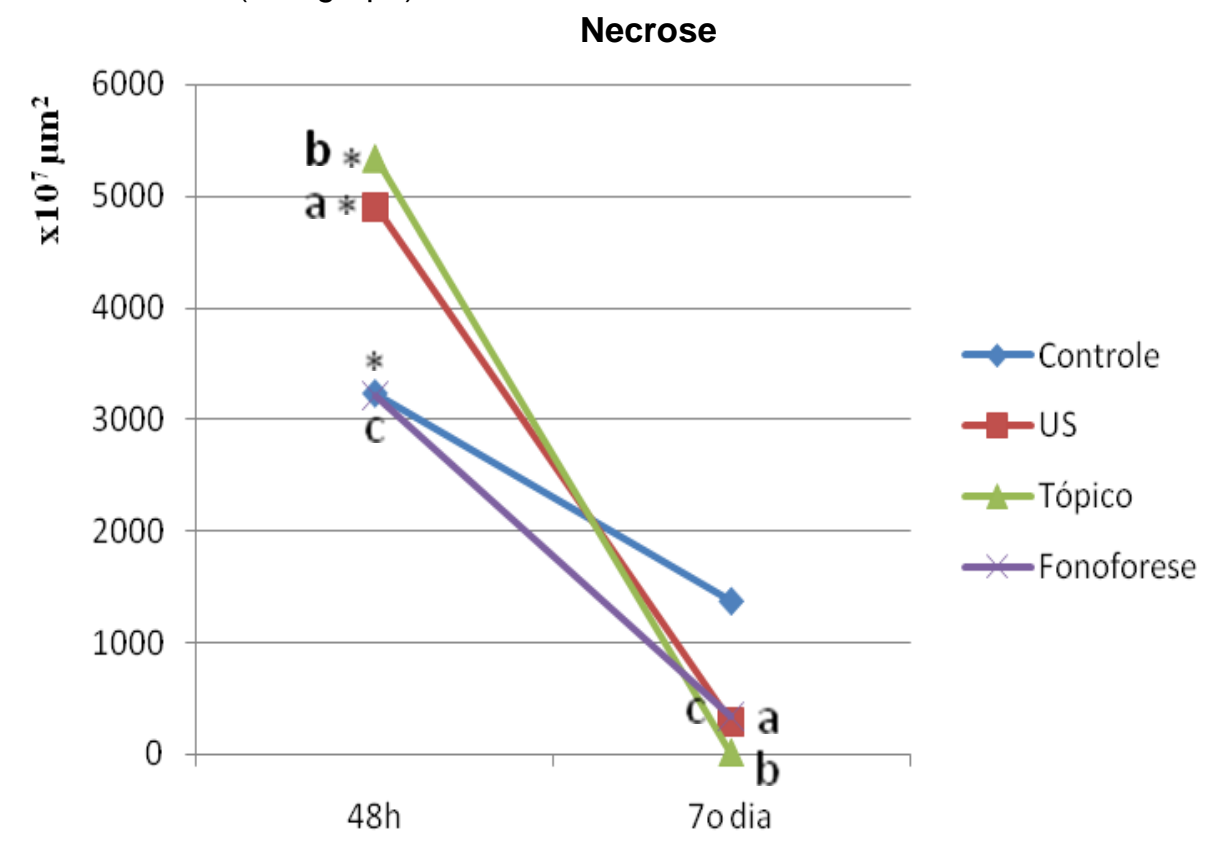

Momento de Eutanásia

Legenda: *Houve significância entre as terapias por US $48 \mathrm{~h}$ e Tópico $48 \mathrm{~h}$ em relação ao grupo controle 48h. ${ }^{a}$ Houve significância entre as terapias por US $48 \mathrm{~h}$ e US $7^{\circ}$ dia. ${ }^{b}$ Houve significância entre as terapias por uso Tópico $48 \mathrm{~h}$ e Tópico $7^{\circ}$ dia. ${ }^{\circ}$ Houve significância entre as terapias por Fonoforese $48 \mathrm{~h}$ e Fonoforese $7^{\circ}$ dia.

Fonte: Marinho, DF, et al., 2017.

\section{Infiltrado inflamatório}

Quanto à intensidade do infiltrado inflamatório presente no tecido muscular analisado, este foi analisado de acordo como o número de células por campo. No momento $48 \mathrm{~h}$ a terapia que se mostrou mais eficaz na redução/controle deste foi à terapia por fonoforese, apesar disso o número de células/campo presente nesse grupo de terapia ainda foi superior aos valores encontrados no grupo controle. E esse padrão ainda foi observado nas terapias por uso tópico e fonoforese. Mas apesar das diferenças observadas ao gráfico, não houve significância entre os grupos testados no momento 48h.

No momento $7^{\circ}$ dia a terapia que se mostrou mais eficaz no controle ao infiltrado inflamatório foi a por uso tópico em relação ao grupo controle. Já nas terapias por US e fonoforese os valores encontrados foram piores que o do grupo controle. Mas apesar disso não houve significância estatística também nas terapias testadas no momento $7^{\circ}$ dia, quando comparado ao grupo controle ou aos outros grupos teste (Gráfico 4). 
Gráfico 4 - Número de células/campo de células do infiltrado inflamatório nos diferentes momentos de eutanásia (48h e $7^{\circ}$ dia). Os resultados estão expressos em média, $n=5 / g r u p o$.

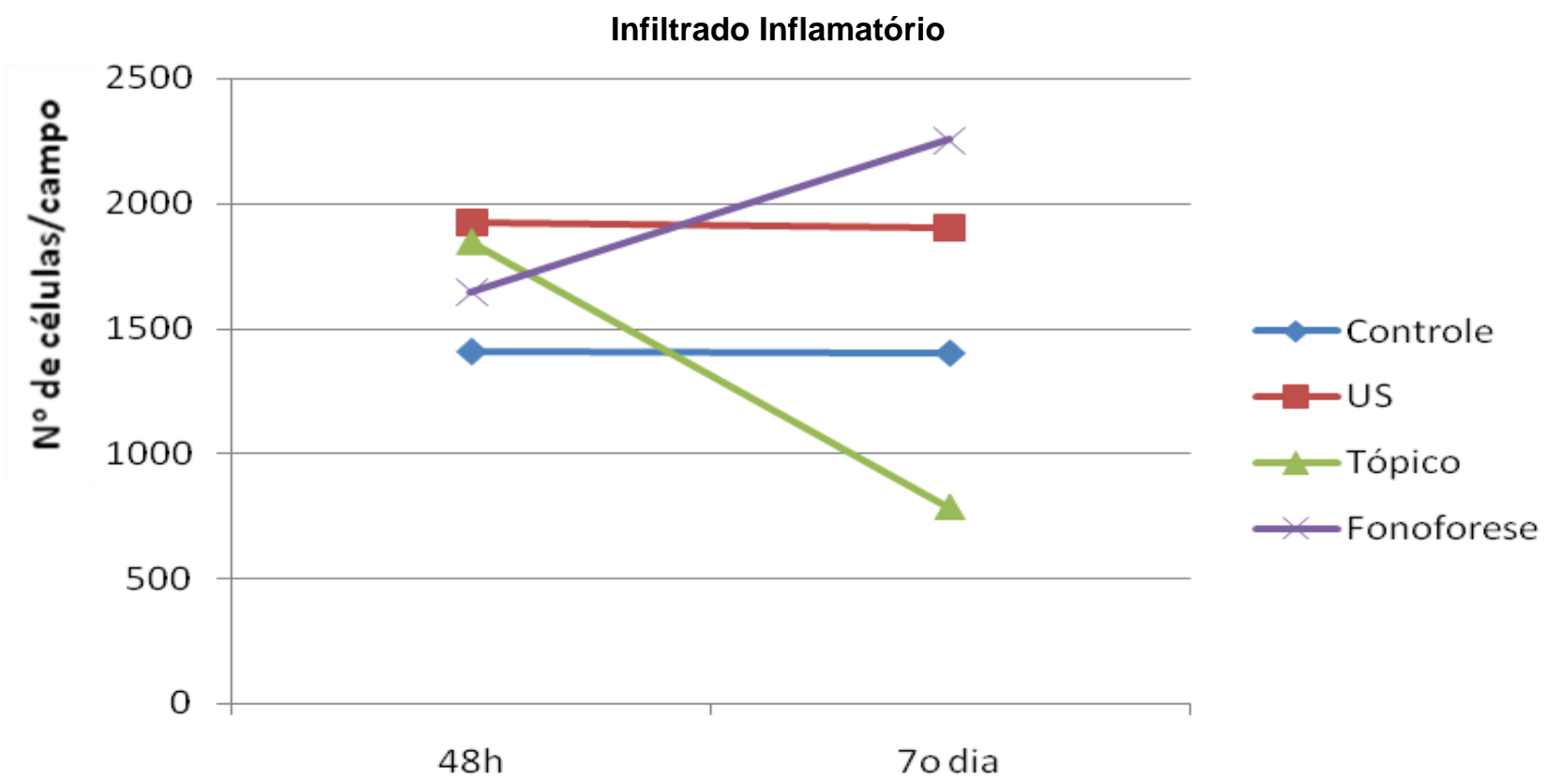

Momento de Eutanásia

Fonte: Marinho, DF, et al., 2017.

\section{Núcleos centralizados}

O número de células com núcleo centralizado presentes no tecido muscular estudado foi analisado de acordo com o número de células por campo. Este resultado demonstra o grau de formação de novo tecido muscular, com a presença de novas células que se apresentam com núcleos centralizados surgidas a partir das células satélites musculares, visto que as células musculares maduras possuem núcleos periféricos. $\mathrm{E}$ como já era esperado, essas células somente foram visualizadas no momento de análise $7^{\circ}$ dia.

No momento $48 \mathrm{~h}$ nenhum dos grupos de terapias apresentaram núcleos centralizados/campo. Em relação ao momento $7^{0}$ dia a terapia com o maior número de células com núcleo centralizado/campo foi à terapia por US, seguida das terapias por fonoforese e uso tópico. Sendo que o uso tópico apresentou valores de células/campo inferiores ao grupo controle.

O que não ocorreu com as outras terapias testadas. Mas, apesar disso, não houve significância estatística entre as terapias testadas em relação ao grupo controle. Só foi observada significância estatística entre as terapias US $7^{\circ}$ dia e Tópico $7^{\circ}$ dia (Gráfico 5). 
Gráfico 5 - Número de células/campo de células com núcleos centralizados nos diferentes momentos de eutanásia (48h e $7^{\circ}$ dia). Os resultados estão expressos em média ( $n=5 /$ grupo).

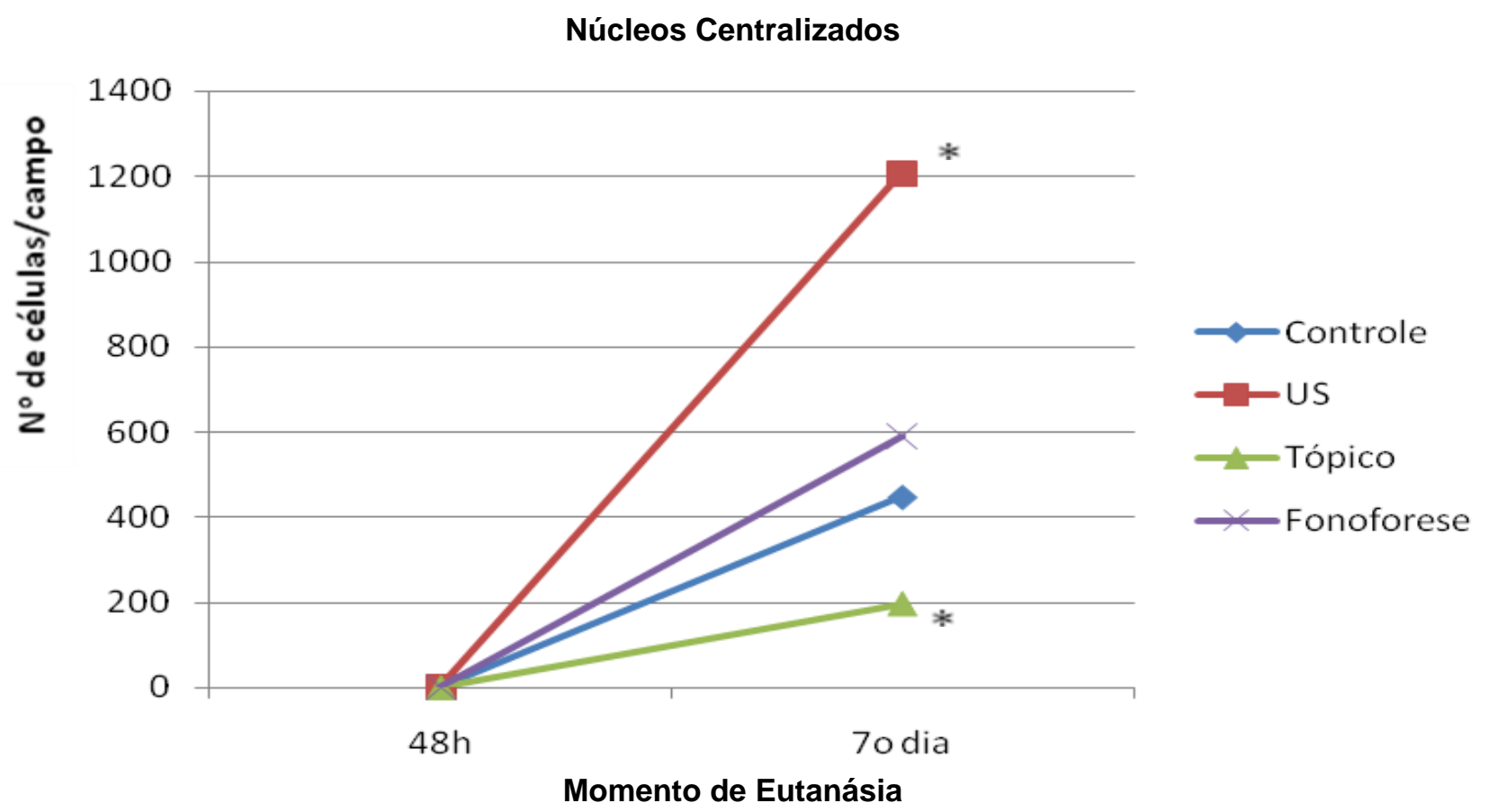

Legenda: Houve significância na diferença entre as terapias US $7^{\circ}$ dia e Tópico $7^{\circ}$ dia.

Fonte: Marinho, DF, et al., 2017.

\section{DISCUSSÃO}

Os melhores resultados para redução das variáveis estudadas foram encontrados nos grupos tópico e fonoforese. Exceto em relação à variável "núcleos centralizados", onde o maior número de núcleos centralizados por campo foi encontrado no grupo US, o que já era esperado devido à propriedade das ondas de ultrassom de acelerar o processo inflamatório, o que leva a agilidade na resolução da inflamação e consequentemente maior agilidade na formação do novo tecido, que pode ser representado pela formação de novas células musculares, a partir da ativação das células satélites na periferia das fibras musculares (PERTILLE A, et al., 2012).

Os resultados encontrados no grupo tópico também confirmam a eficiência do uso tópico tradicional sobre a pele da copaíba com mínima fricção ou "massagem", o que comprova a sua eficiência na resolução do quadro inflamatório, já atribuída à copaíba. Podemos comprovar ainda que C. duckei permaneceu farmacologicamente eficiente quando da sua veiculação através da formulação em gel, como também foi observado em pesquisa semelhante, por não atenuar as ondas do ultrassom (MARINHO DF, et al., 2017) e em pesquisa realizada com nanoemulsão de OR da espécie C. reticulata (LIMA TCP, et al., 2020).

Os resultados positivos do grupo fonoforese respondem positivamente ao questionamento quanto a sua eficiência farmacológica quando veiculado através do gel de OR de C. duckei. No entanto, quando comparamos ao efeito encontrado no grupo tópico, estes foram bem semelhantes, não havendo como o esperado, incremento do resultado pela soma dos efeitos terapêuticos já reconhecidos da copaíba e do US. Assim, isso não justificaria o uso de um equipamento quando apenas com o uso tópico seria possível obter os mesmos efeitos. Isso se justifique possivelmente a "competição" das propriedades anti-inflamatórias do OR e pró-inflamatórias do US (LEANDRO LM, et al., 2012; KOEKE PU, et al., 2005).

Não foram encontrados na literatura estudos que tenham testado a atividade anti-inflamatória e de cicatrização muscular do OR de C. duckei através da técnica de fonoforese. No entanto, existem algumas pesquisas que já puderam comprovar os efeitos terapêuticos positivos de outras plantas medicinais através 
da técnica de fonoforese (FURTADO RAA, et al., 2019). Como exemplo, podemos citar os trabalhos realizados com arnica, andiroba, calêndula, aloe vera e até mesmo outras espécies de copaíba, como a $C$. reticulata (ALFREDO PP, et al., 2009; BRITO MVH, et al., 2006; RICOLDY DS, et al., 2010; MAIA FILHO ALM, et al., 2010; MIRANDA DHS, et al., 2016).

E trabalhos que avaliaram e comprovaram efeitos positivos na aplicação por fonoforese de fármacos como hidrocortisona, diclofenaco dietilamônio, cetoprofeno e dimetilsulfóxido (DMSO). No entanto, por meio de metodologias de aplicação e análise diferentes, apesar de algumas serem bem semelhantes (KOEKE PU, et al., 2005; SOUZA J, et al., 2013; SILVEIRA PCL, et al., 2010).

Recomendamos estudos adicionais de permeação e de ação terapêutica no $14^{\circ}$ e $21^{\circ}$ dias após a lesão muscular, com continuação da aplicação das terapias até esses momentos. Com o objetivo de fazer uma análise completa de todo o processo de recuperação de uma lesão muscular, bem como a dosagem de marcadores inflamatórios.

\section{CONSIDERAÇÕES FINAIS}

Quanto ao efeito terapêutico, o gel fitoterápico de copaíba da espécie C. duckei 10\% mostrou resultados mais eficazes para o processo de reparação muscular na fase inflamatória por via tópica, sendo seguido pelo tratamento por fonoforese. O surgimento de núcleos centralizados foi mais adiantado ao utilizar o US para tratamento. O tratamento de US pulsado $1 \mathrm{MHz}$ a $20 \%$, com $0,6 \mathrm{~W} / \mathrm{cm}^{2}$ por um minuto indica a possibilidade de antecipação da formação de novas células musculares pela observação dos núcleos centralizados. Mostraram-se positivos os benefícios da utilização do gel fitoterápico de C. duckei $10 \%$ no processo de reparação muscular.

\section{AGRADECIMENTOS E FINANCIAMENTO}

Financiamento da Fundação Amazônia de Amparo a Estudos e Pesquisas (FAPESPA), ACT № 05/2013EDITAL: 005/2013 - Bolsas de mestrado.

\section{REFERÊNCIAS}

1. ALFREDO PP, et al. Effects of phonophoresis with Arnica montana onto acute inflammatory process in rat skeletal muscles: An experimental study. Ultrasonics. 2009; 49: 466-471.

2. BRITO MVH, et al. Efeito dos óleos de andiroba e copaíba na miosite induzida em ratos. Revista Paraense de Medicina. 2006; 20(2).

3. CARVALHO JCT, et al. Topical antiinflammatory and analgesic activities of Copaifera duckei Dwyer. Phytother. Res. 2005; 19: 946-950.

4. FURTADO RAA, et al. Ação do gel Anacardium Occidentale L. associado ao ultrassom terapêutico no processo de cicatrização em camundongos. Revista Saúde (Sta. Maria). 2019; 45(2).

5. JÄRVINEN TA, et al. Muscle injuries: biology and treatment. Am J Sports Med. 2005; 33(5): 745-64.

6. KOEKE PU, et al. Comparative study of the efficacy of the topical application of hydrocortisone, therapeutic ultrasound and phonophoresis on the tissue repair process in rat tendons. Ultrasound in Med. \& Biol., 2005; 31(3): 345-350.

7. LEANDRO LM, et al. Chemistry and Biological Activities of Terpenoids from Copaiba (Copaifera spp.) Oleoresins. Molecules. 2012; 1420-3049.

8. LIMA TCP, et al. Desenvolvimento de nanogel de Copaifera reticulata sobre a lesão muscular em ratos usando fonoforese. Saúde e Pesqui. 2020; 13(1): 181-192.

9. MACBRIER NM, et al. Reliability and validity of a novel muscle contusion device. Journal of Athletic Training. 2009; 44(3): 275-278.

10. MAIA FILHO ALM, et al. Comparative study of the topical application of aloe vera gel, therapeutic ultrasound and phonophoresis on the tissue repair in collagenase-induced rat tendinitis. Ultrasound in Med. \& Biol., 2010; 36(10): $1682 \mathrm{e} 1690$.

11. MARINHO DF, et al. Avaliação da transmissibilidade ultrassônica do gel fitoterápico de Copaifera duckei Dwyer. Pesq. Vet. Bras. 2017; 37(5): 516-520.

12. MIRANDA DHS, et al. Estudo comparativo da ação anti-inflamatória do óleo-resina da Copaifera reticulata em modelos farmacológicos experimentais em camundongos. Fisioter Bras. 2016; 17(4): 305-12. 
13. MONTES LV, et al. Evidências para o uso da óleo-resina de copaíba na cicatrização de ferida - uma revisão sistemática. Revista Natureza on line. 2009; 7 2): 61-67.

14. OLIVEIRA RF, et al. Effect of low-intensity pulsed ultrasound on 1929 fibroblasts. Archivos Medical Scientia, 2011; 7(2): 224-229.

15. PERTILLE A, et al. Avaliação da regeneração muscular em animais idosos após tratamento com laser de baixa intensidade. Revista Brasileira de Fisioterapia, São Carlos. 2012; 16(6): 495-501.

16. PIERI FA, et al. Óleo de copaíba (Copaifera sp.): histórico, extração, aplicações industriais e propriedades medicinais. Revista Brasileira de Plantas Medicinais, Botucatu. 2009; 11(4): 465-472.

17. RIBEIRO R. Efeito do ultra-som terapêutico pulsado na proliferação e atividade gelatinolítica de células musculares. Dissertação (Mestrado em Ciências da Reabilitação) - Programa de Pós-graduação em Ciências da Reabilitação. Universidade Nove de Julho, São Paulo, 2009; 58p.

18. RICOLDY DS, et al. Efeito do ultrassom associado ao gel de calêndula sobre a atividade reparadora em lesões musculares experimentais. Acta Scientiarum. Health Sciences. Maringá. 2010; 32(2): 135-140.

19. SILVEIRA PCL, et al. Effects of therapeutic pulsed ultrasound and dimethylsulfoxide (DMSO) phonophoresis on parameters of oxidative stress in traumatized muscle. Ultrasound in Med. \& Biol., 2010; 36(1): 44-50.

20. SOUSA FILHO LA, et al. Therapeutic ultrasound associated with copaiba oil reduces pain and improves range of motion in patients with knee osteoarthritis. Fisioter. Mov., Curitiba. 2017; 30(3): 443-451.

21. SOUZA J, et al. Effect of phonophoresis on skin permeation of commercial anti-inflammatory gels: sodium diclofenac and ketoprofen. Ultrasound in Med. \& Biol., 2013; 39(9): 1623-1630.

22. TOMAZONI SS. Efeito da sinvastatina na lesão induzida por estiramento passivo em ratos. Dissertação (Mestrado em Farmacologia) - Instituto de Ciências Biomédicas. Universidade de São Paulo, São Paulo, 2011; 96 p.

23. 23.VICTOR EG, et al. Pulsed ultrasound associated with gold nanoparticle gel reduces oxidative stress parameters and expression of pro-inflammatory molecules in an animal model of muscle injury. Journal of Nanobiotechnology, 2012. 